1990-01-01

\title{
Design of High Performance Soft X-Ray Windows
}

\author{
Raymond T. Perkins \\ rperkins@moxtek.com \\ David D. Allred \\ allred@byu.edu \\ Larry V. Knight \\ larry_knight@byu.edu \\ James M. Thorne
}

Follow this and additional works at: https://scholarsarchive.byu.edu/facpub

Part of the Astrophysics and Astronomy Commons, and the Physics Commons

\section{Original Publication Citation}

Raymond T. Perkins, David D. Allred, Larry V. Knight, and James M. Thorne, "Design of high performance, soft x-ray windows," Advances in X ray Analysis, 33, Charles S. Barrett, Editor (Plenum, New York, 199), pp. 615 622. http://www.icdd.com/resources/axasearch/ search_based_on_vol.asp

\section{BYU ScholarsArchive Citation}

Perkins, Raymond T.; Allred, David D.; Knight, Larry V.; and Thorne, James M., "Design of High Performance Soft X-Ray Windows" (1990). Faculty Publications. 1197.

https://scholarsarchive.byu.edu/facpub/1197

This Peer-Reviewed Article is brought to you for free and open access by BYU ScholarsArchive. It has been accepted for inclusion in Faculty Publications by an authorized administrator of BYU ScholarsArchive. For more information, please contact ellen_amatangelo@byu.edu. 


\title{
DESIGN OF HIGH PERFORMANCE SOFT X-RAY WINDOWS
}

\author{
Raymond T. Perkins, David D. Allred, Larry V. Knight \\ Department of Physics and Astronomy \\ and \\ Center for X-ray Imaging \\ Brigham Young University, Provo, Utah 84602
}

James M. Thorne

Department of Chemistry

and

Center for X-ray Imaging

Brigham Young University, Provo, Utah 84602

\section{INTRODUCTION}

$\mathrm{X}$-ray windows are used in sources and detectors to separate the neighborhood of the x-ray generation or detection from the use environment. While each use has its own requirements, there are some principles that should be used in designing an optimal $\mathrm{x}$-ray window. Because $\mathrm{x}$ rays are absorbed to some extent by all materials, minimizing absorption is one criterion in preparing windows, Also, for most uses there is a pressure difference across the window so that ensuring pinhole-free structure and sufficient mechanical strength to support the differential is another criterion for window design. Traditionally, absorption is minimized by fabricating the window with lower atomic number (low Z) elements such as Be, B or C. However, the wavelength (energy) region of interest becomes a very important complicating factor.

Over the years many different materials have been used as windows for soft $\mathrm{x}$ rays. A primary use has been for proportional counters. More recently interest has developed for $\mathrm{Si}(\mathrm{Li})$ detectors. The materials used to date for proportional counters include: polypropylene, lexan, and formvar ${ }^{1-4}$. Materials used for $\mathrm{Si}(\mathrm{Li})$ detectors have been $\mathrm{Be}, \mathrm{BN}_{x}$, formvar, a-C:H (diamond-like carbon), and mylar ${ }^{5}$. The purpose of this paper is to discuss the design of $\mathrm{x}$-ray windows with particular emphasis on windows for detectors in the soft $x$-ray region. This is because existing windows can typically be made thin enough to have very good transmission for the harder $\mathrm{x}$-rays.

\section{MODELING AND METHODOLOGY OF STUDY}

For this study, two primary criteria were chosen for window study: film transmission and material integrity. Evaluation of the first is amenable to computer simulation 
and this is the approach taken in this study. The second is more subjective and will be treated in a descriptive fashion. While materials can be ranked according to bulk moduli and yield strengths, the integrity and mechanical properties of thin films are very dependent on preparation techniques and microstructure.

The calculations were done using a computer code called UM which was designed and written by us. It is written in FORTRAN 77 and was designed to do a wide variety of calculations involving $x$-rays, thin films, and crystals. It accesses a data base of atomic scattering factors. For the problem at hand these are used to calculate optical constants.

The atomic scattering factors weré obtained from Henke's tables and expanded at BYU and Lawrence Livermore National Laboratory. Beer's law was used in optical calculations. This is justifiable since the films are always much thicker than the wavelength of soft $x$ rays and hence interference effects are negligible. In addition, the reflection of $\mathrm{x}$ rays from front and back surfaces of the windows at near normal incidence was calculated to be much smaller than $10^{-4}$ and thus could be neglected over the whole range,

Calculations were made over the range $10 \AA$ to $70 \AA$ ( $170 \mathrm{eV}$ to $1200 \mathrm{eV}$ ). X rays of this range are too soft to be transmitted through the beryllium windows used in typical $\mathrm{Si}(\mathrm{Li})$ detectors. This ranges includes the $K_{\alpha}$ radiation of all elements with atomic numbers from $\mathrm{Z}=5$ to 11 (boron to sodium).

\section{RESULTS}

In Figure 1 and Figure 2 is shown the computed transmission of windows which have typically been used for $\mathrm{x}$-ray applications. Typical thicknesses were used in the computations and are noted in the figure. The bottom curve is that of $8 \mu \mathrm{m}(0.3$ mil) beryllium (this is the thinnest rolled Be foil used for $\mathrm{Si}(\mathrm{Li})$ detectors). Such a thickness allows only about $45 \%$ of the sodium $K_{\alpha}$ radiation to be transmitted and a negligible fraction of $x$ rays less energetic than that. (In practice the transmission of sodium $K_{\alpha}$ radiation is much less than $45 \%$. This is due in part to at least two causes. First, the Be is typically overcoated with a polymer to plug the holes that are usually found in such thin rolled Be. Second, since it is rolled, there will be a high percentage of beryllium oxide. This oxygen causes undesirable absorption of soft $\mathrm{x}$ rays.)

Another common window is $6 \mu \mathrm{m}\left(\frac{1}{4} \mathrm{mil}\right)$ polypropylene, metallized with aluminum ( $\sim 20 \mathrm{~nm}$ thick). This is used in proportional counters and is the next most transmissive material/thickness combination. Polypropylene windows $2 \mu \mathrm{m}$ and 1 $\mu \mathrm{m}$ thick are also used. Curves for all three are shown in the figures.

It will be noted that the polypropylene is much more transmissive than is the typical $\mathrm{Be}$ window for the soft $\mathrm{x}$ ray region, particularly on the low energy side of the $\mathrm{C}$ absorption edge. One can see the effect of the carbon content by the rather dramatic absorption edge; the nitrogen $K_{\alpha}$ radiation is highly attenuated. In this respect, polypropylene resembles a carbon $\mathrm{K}$-edge filter (allows carbon $\mathrm{x}$ rays to pass but blocks more energetic, particularly nitrogen, $x$ rays). This is an important design point since any material which is predominantly a single element or a single element with hydrogen will act as an edge filter. Polypropylene is not a single element but acts as such for soft $x$ rays since the hydrogen is transparent and can be ignored. The transmission curve for $400 \mathrm{~nm}$ of diamond is shown in Figure 3. Like polypropylene it acts as an edge filter, extinguishing nitrogen $x$ rays. However, because of its higher density and low hydrogen content, $0.4 \mu \mathrm{m}$ of diamond is equivalent to about $1.9 \mu \mathrm{m}$ of polypropylene.

There is a variety of materials that incorporate various low- $Z$ elements into-their structure. The transmission of $400 \mathrm{~nm}$ of formvar (polyvinyl formal), which has been 


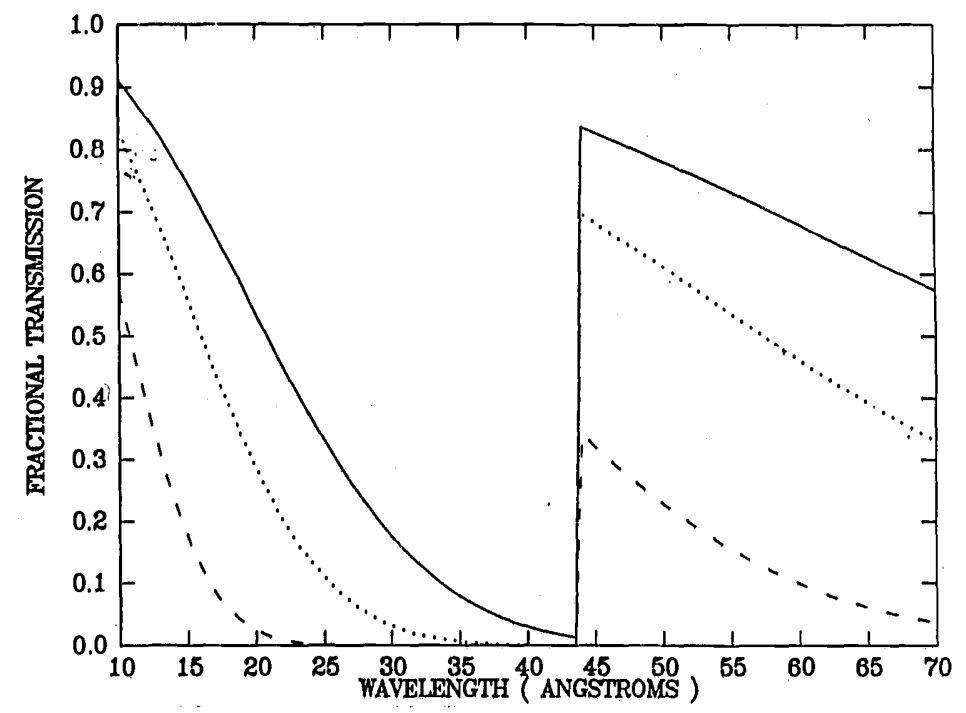

Figure 1. Transmission for $1 \mu \mathrm{m}$ (solid line), $2 \mu \mathrm{m}$ (dotted), and $6 \mu \mathrm{m}$ (dashed) thick polypropylene.

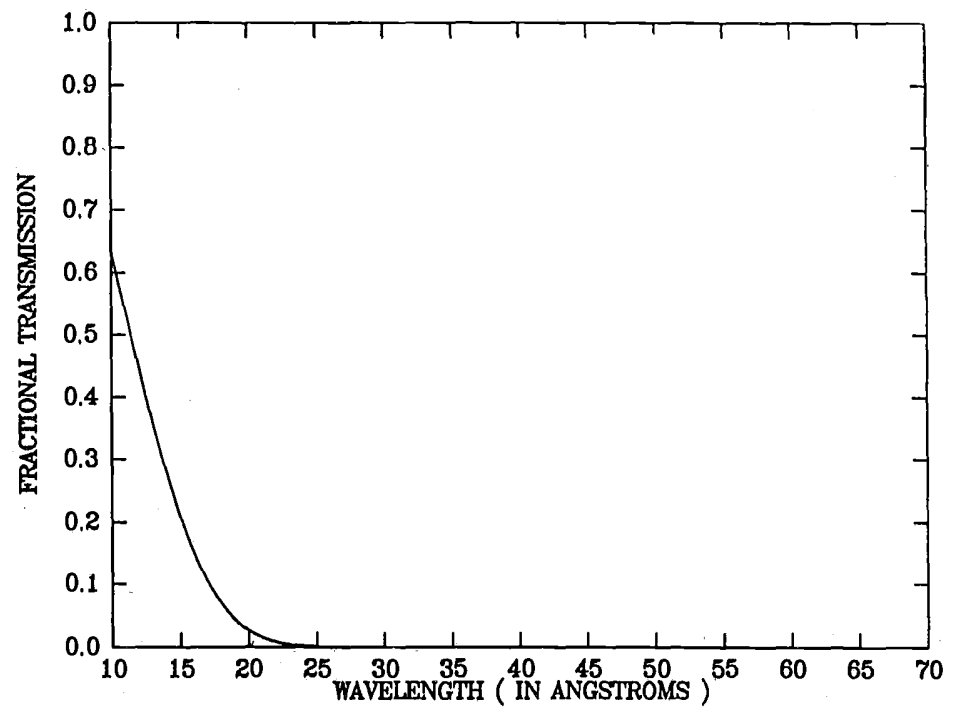

Figure 2. Transmission for $8 \mu \mathrm{m}$ thick beryllium.

used in the past for proportional counter windows, is shown in Figure 3. Another material which may be used for soft $x$-ray windows is a boron containing material such as BN. Also shown in Figure 3 is the transmission for $400 \mathrm{~nm}$ of hexagonal BN. Note that for equivalent thicknesses of $400 \mathrm{~nm}, \mathrm{BN}$ windows, and especially formvar windows, are much more transparent than diamond for $\mathrm{F}, \mathrm{O}$, and $\mathrm{N} \mathrm{x}$ rays. In this case the BN falls below diamond for carbon $x$-ray transmission but is still useable at this thickness.

The superiority of the compound materials comes about for two reasons. First, formvar has a lower density than diamond, and second but more important than 


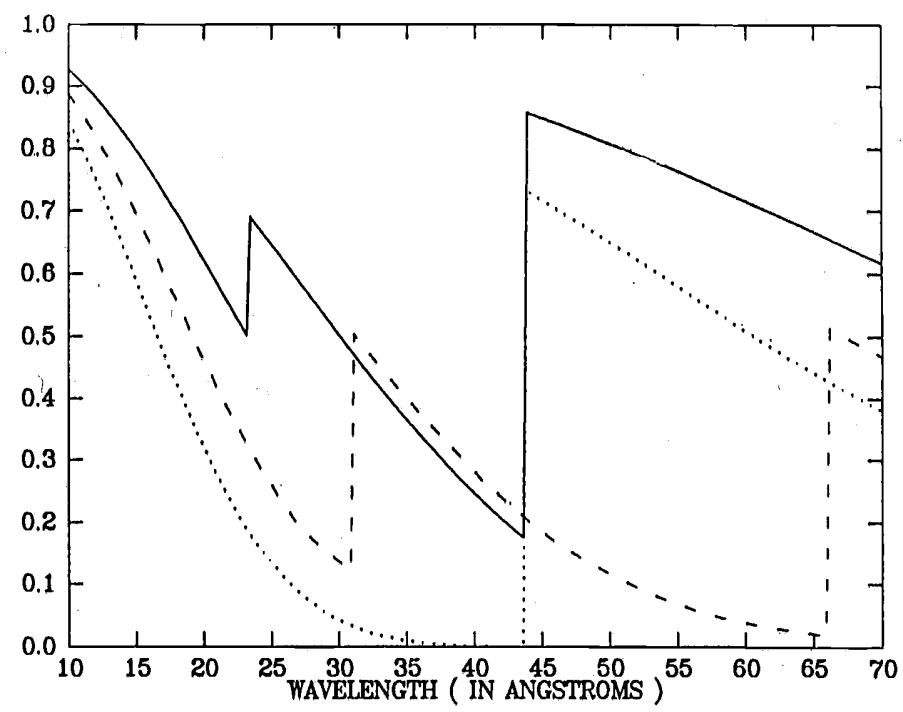

Figure 3. Transmission for $400 \mathrm{~nm}$ of formvar (solid line), diamond (dotted), and $\mathrm{BN}$ (dashed).

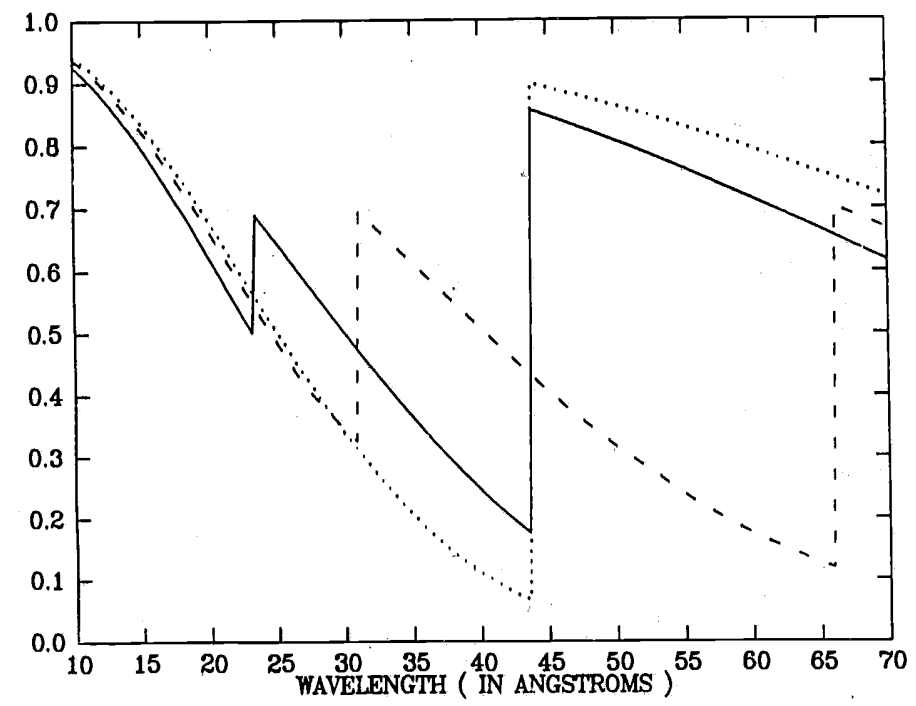

Figure 4. Transmission for $400 \mathrm{~nm}$ of formvar (solid line), $138.8 \mathrm{~nm}$ of diamond (dotted), and $213.3 \mathrm{~nm}$ of BN (dashed).

density, it is not a single element. It contains a mixture of carbon and oxygen. The importance of this second point can be seen in Figure 4, which is the transmission of the same three materials as in Figure 3 but for the same mass per unit area instead of equal thickness. This suggests that the best window material from the point of view of high transmission for a given mass thickness would be a mixture of $\mathrm{C}, \mathrm{N}$, and $\mathrm{O}$. Hydrogen would be used as required to tie up the dangling bonds. A transmission curve for such a material is shown in Figure 5, This is in contrast with 


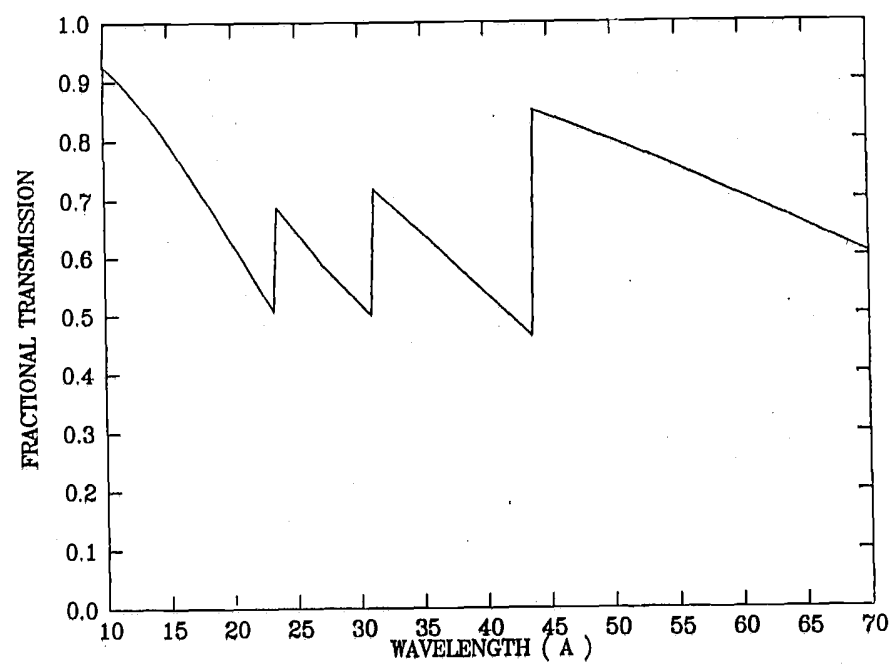

Figure 5. Transmission for $400 \mathrm{~nm}$ of an idealized material.

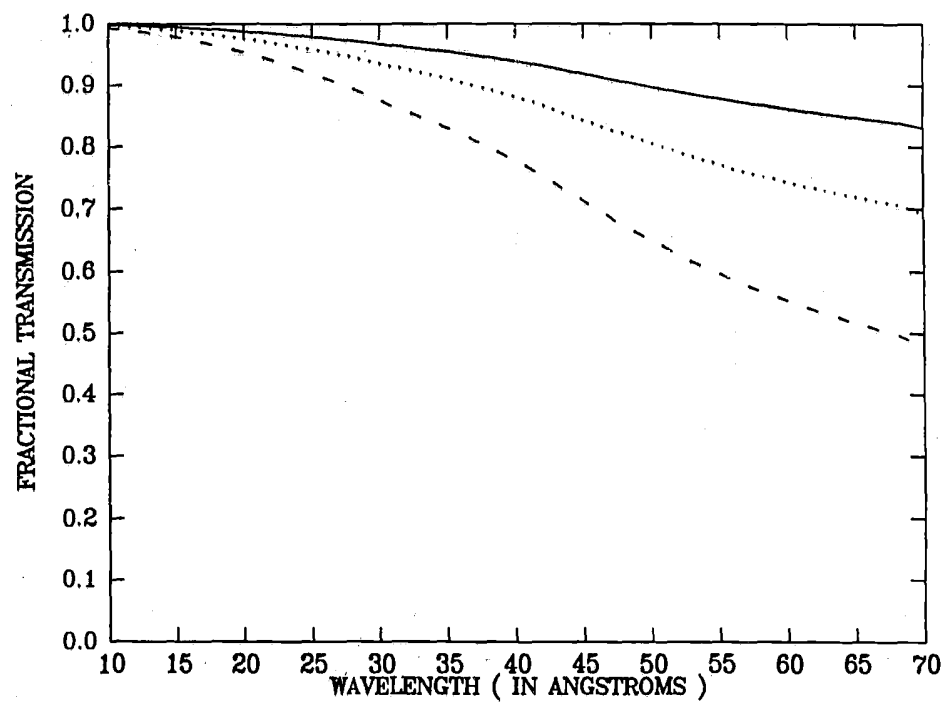

Figure 6. Transmission for 10 (solid line), 20 (solid line) and $40 \mathrm{~nm}$ of Al (dashed).

single element windows like diamond which are "colored" in that they transmit the certain wavelengths better than others. Windows with 1:1:1 mixtures of the elements will transmit roughly equivalently the wavelengths that correspond to each element. Such windows would be approximately neutral density for elemental soft $\mathrm{x}$ rays and can be termed "gray windows". Producing a "gray window" would be a noteworthy achievement. Probably it will not be possible to produce such a window with a 1:1:1 mixture exactly, but in practice it may be possible to develop a compound with nearly these ratios. It should be noted some of the families of materials which contain $\mathrm{C}, \mathrm{N}$, and $\mathrm{O}$ are the polyimides, nylon and Kevlar.

Nonmetallic $\mathrm{x}$-ray windows are normally metallized. In the case of proportional counters to prevent charge build up. In the case of $\mathrm{Si}(\mathrm{Li})$ detectors this is to block the 
transmission of infrared and visible light which would otherwise generate unwanted noise. The metallic coating should be as thin as possible to to minimize x-ray absorption. The metal almost invariably chosen for this task is aluminum. It shows about the highest ratio of visible light extinction to soft $\mathrm{x}$-ray extinction of any metal and is self passivating in air. It is also a safer material to work than beryllium. We have calculated the transmittance of light as a function of metal thickness using Airy's formula $e^{6}$ and assuming normal incidence. The calculations show that $\mathrm{Al}$ is superior to $\mathrm{Be}$ for blocking light. For example, at a wavelength of $578 \mathrm{~nm}$ a pair of $20 \mathrm{~nm}$ Al layers have a combined transmittance of $0.504 \%$. This is to be compared with a transmittance of $43.04 \%$ for similar Be layers. Even though Be has a low mass absorption coefficient for $\mathrm{x}$ rays, the thickness required makes it inferior to Al for blocking transmission of visible and UV light to $\mathrm{Si}(\mathrm{Li})$ detectors. We have not found a metal superior to $\mathrm{Al}$ in this regard. The soft $\mathrm{x}$-ray transmission of various thicknesses of $\mathrm{Al}$ are shown in Figure 6. In the visible range $40 \mathrm{~nm}$ of aluminum extinguishes more than $95 \%$ of the incident light. The overall transmission of the $\mathrm{x}$ rays is the product of the film and the aluminum transmission.

The $\mathrm{x}$-ray transmission is only one issue. The window must possess mechanical properties commensurate with the task of maintaining a pressure differential of approximately one atmosphere for long periods of time and/or under cycling conditions. The properties which go into achieving this include film mechanical strength, film perfection, and the support structure. It must have sufficient strength to survive a pressure differential of over one atmosphere and sufficient rigidity not to flow. For an aluminized polymer such as polypropylene, flow or stretching can cause cracking of the aluminum thus compromising the window.

As has been discussed above, it is desirable for transmission purposes to make a window as thin as possible. As a material is made thinner, there comes a point at which it is not mechanically robust or reliable. This will depend upon the area being spanned. The larger the area, the greater is the practical limiting thickness. It was long ago realized that with some kind of support grid, effectively larger areas could be covered with thin films. Recently our group at BYU developed a method of making a very close-spaced grid for the support of thin films for the purpose of soft $\mathrm{x}$-ray windows for $\mathrm{Si}(\mathrm{Li})$ detectors. See Figure 7. A patent is pending for the method and resulting structure. The method consists of micromachining a grid from silicon. Typically the structure has ribs $25 \mu \mathrm{m}$ wide separated by $100 \mu \mathrm{m}$, resulting in a fractional free area of $80 \%$. Windows with such a support structure have been made using formvar, $\mathrm{Si}_{3} \mathrm{~N}_{4}, \mathrm{a}-\mathrm{C}: \mathrm{H}$, and other materials.

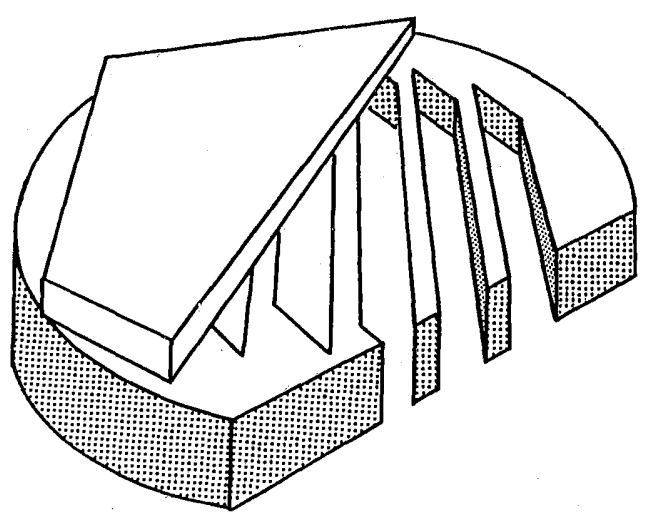

Figure 7. Cut-away schematic of $x$-ray window showing micromachined support structure and film. 


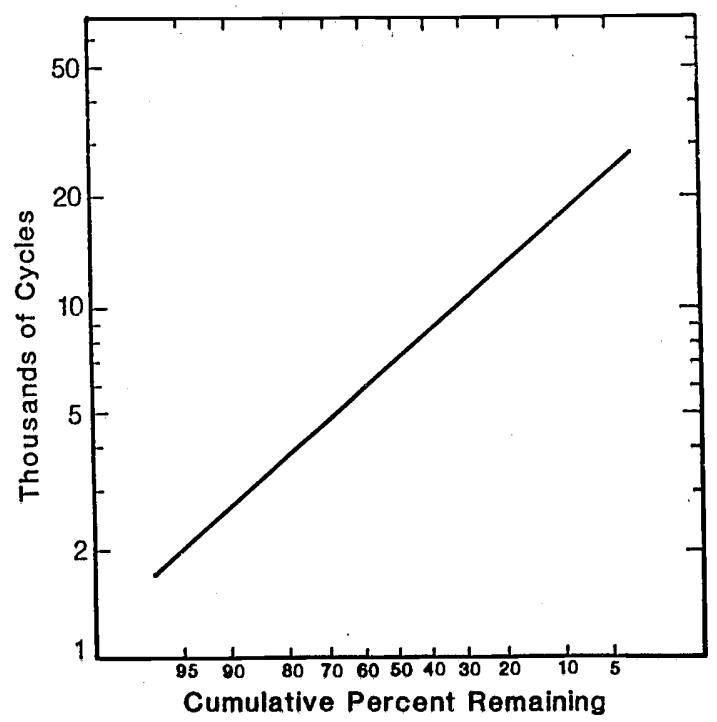

Figure 8. Pressure cycie results for $400 \mathrm{~nm}$ of aluminized formvar on $80 \%$ transmission grid.

With such a structure, film strength rarely is a serious issue. Calculations show that as little as $1 \mathrm{~nm}$ of $\mathrm{Si}_{3} \mathrm{~N}_{4}$, if the material were to possess bulk properties and were free of defects, when stretched over a $200 \mu \mathrm{m}$ opening could support a pressure differential of one atmosphere. Such a thin film is not practical since thin films rarely possess bulk properties and a single weak spot could render worthless an otherwise acceptable window. Window integrity is thus usually more important than bulk yield strength as a window selection criterion. It is well known that film perfection depends on film formation. Such factors include care, cleanliness, and choice of formation techniques.

Film structure must fulfill another role with $\mathrm{Si}(\mathrm{Li})$ detectors. It must block the diffusion of gases into the region of the detector. This puts further constraints on the microstructure of the window membrane and particularly discriminates against polycrystalline materials such as diamond. For polymer windows for $\mathrm{Si}(\mathrm{Li})$ detectors then, gas permeability is an additional reason for aluminization.

Windows made of $400 \mathrm{~nm}$ of formvar with $40 \mathrm{~nm}$ of Al have been pressure cycled. The films were on a silicon support structure with a bar width of $25 \mu \mathrm{m}$ and a spacing of $100 \mu \mathrm{m}$. The active area was circular with a diameter of $6 \mathrm{~mm}$. Typically these have very low visible light transmission and have a He leak rate of less than $10^{-10}$ std.atm.-cc/sec. The high pressure side was pressure cycled to 15 PSIG of argon. A pressure sensor was on the other side of the window. The time to pressurize and depressurize was $1 \mathrm{sec}$. Cycle times have been $2 \mathrm{sec}$. and $6 \mathrm{sec}$. There was no discernable difference in results for the two cycle times. The results of this stress test are summarized in Figure 8. The data have been fit to a lognormal curve (see Appendix). These data indicate a $\mathrm{T}_{50}$ (median cycles to fail) of 5800 cycles. The mean cycles to fail is approximately 5000 .

\section{CONCLUSION}

Criteria for designing soft $x$-ray windows have been discussed. It was shownthat a thin material containing several elements, most notably $\mathrm{O}, \mathrm{N}$, and $\mathrm{C}$ will 
create a reasonably neutral window for the $10 \AA$ to $70 \AA$ region. Furthermore, it was pointed out that materials such as diamond or polypropylene are essentially edge filters. A structure which allows creation of very thin, high transmission, and mechanically strong windows was disclosed. Pressure cycling data for such a window were presented.

\section{APPENDIX}

The lognormal distribution is probably the most common wearout distribution in nature. It is defined as follows:

The probability density is given by

$$
f(T)=\frac{0.4343}{T \sigma \sqrt{2 \pi}} \exp \left\{-\frac{1}{2}\left(\frac{\log \frac{T}{T_{50}}}{\sigma}\right)^{2}\right\}
$$

where $\log =\log _{10}, T$ is the independent parameter; in our case it is the number of cycles to failure, and $T_{50}$ is the number of cycles for $50 \%$ of the samples to fail. It is very difficult to obtain sufficient data to "divine" the probability density itself, but it is easy to get the cumulative probability distribution.

The cumulative probability distribution is

$$
F(T)=\int_{x=0}^{x=T} \frac{1}{\sqrt{2 \pi}} \exp \left\{-\frac{1}{2}\left(\frac{\log \frac{x}{T_{50}}}{\sigma}\right)^{2}\right\} d\left(\frac{\log \frac{x}{T_{50}}}{\sigma}\right),
$$

where $\sigma$ is found from

$$
\sigma=\log T_{50}-\log T_{16}
$$

and where $T_{16}$ is the number of cycles for $16 \%$ cumulative failures.

\section{REFERENCES}

1. B.L. Henke, et al, Adv. X-Ray Anal., $\underline{8}, 277(1965)$

2. B.L. Henke, et al, Adv. X-Ray, Anal., 18 ,76(1975)

3. G.D. Borley, et al, "A Method of Producing Mounted Thin Windows for X-Ray Spectrometer Flow Counters", X-Ray Spectrometry, Vol. 5, pp 13-15, 1976.

4. F. Williamson, et al, "Thin Films for X-Ray Astronomy", Rev. Sci. Instrum., vol. 46, pp 50-52, 1975.

5. S. Priyokumar Singh, et al, "Aluminized Mylar as $\mathrm{Si}(\mathrm{Li})$ Detector Window For X-Ray Fluorescence Spectrometer", Nuclear Instruments and Methods vol. 167, pp 223-225, 1979.

6. P. Yeh, Optical Waves in Layered Media, pp 90-97, Wiley, N.Y. (1988) 